\title{
Editorial
}

\section{Long-Term Changes in the Atmosphere}

The subject of trends in the atmosphere, which involves among several other topics, the global warming of the lower atmosphere and cooling of the middle and upper atmosphere, is of great interest to meteorologists, geoscientists and environmental scientists. The scope of this special issue is to include studies of trends and long-term variations of the different layers of the atmosphere linked to the increase in greenhouse gases, long term variations in solar and geomagnetic activity, secular variations of the Earth's magnetic field, or any other possible cause of trends in the atmosphere.

The three papers included in this issue deal with trends in the middle and upper atmosphere, which are an important link in the study of the global change that is taking place in the Earth system and also in the detection of its sources, among which is the worrying anthropogenic factor.

The first paper, by Bravo et al., analyzes trends in the annual and semiannual components of the peak electron density in the F2 layer of the ionosphere, NmF2. They suggest that determining the cause of the NmF2 semiannual component long-term changes would be a clue for understanding trends in $\mathrm{NmF} 2$ itself. In the second paper I study long-term variations in the critical frequency of the F2 layer, foF2, with which NmF2 is deduced. Several possible causes are analyzed in a complex scenario. The third paper, by Zossi de Artigas and Fernandez de Campra, deals with stratosphere temperature trends which are theoretically expected to decrease as a consequence of the increasing greenhouse gases concentration.

The three papers aim at contributing to elucidate the causes of the global change, taking place, as the word "global" suggest, in the entire Earth and at all atmospheric layers. And, citing one of the papers in this issue: "Why is it important to understand and measure the low, middle and upper atmosphere trends during the last decades? We live in the Earth and we want to understand and predict the atmosphere behavior which is essential for human life. And, in the present context, an understanding of the atmosphere variations is an essential focus of climate science, which is seeking to determine the extent to which human activities are altering the planetary energy balance through the emission of greenhouse gases and pollutants".

I would like to acknowledge the authors, reviewers and Bentham Science Publishers for making possible this issue on a field which is essential for global warming and climate change predictions and mitigation policies.

Ana G. Elias

(Guest Editor)

Universidad Nacional de Tucuman - CONICET

Facultad de Ciencias Exactas y Tecnologia

Departamento de Fisica

Av. Independencia 1800

4000 Tucumán

Argentina

E-mails: anagelias@yahoo.com, aelias@herrera.unt.edu.ar

(C) Ana G. Elias; Licensee Bentham Open.

This is an open access article licensed under the terms of the Creative Commons Attribution Non-Commercial License (http: //creativecommons.org/licenses/by$\mathrm{nc} / 3.0 /$ ) which permits unrestricted, non-commercial use, distribution and reproduction in any medium, provided the work is properly cited. 